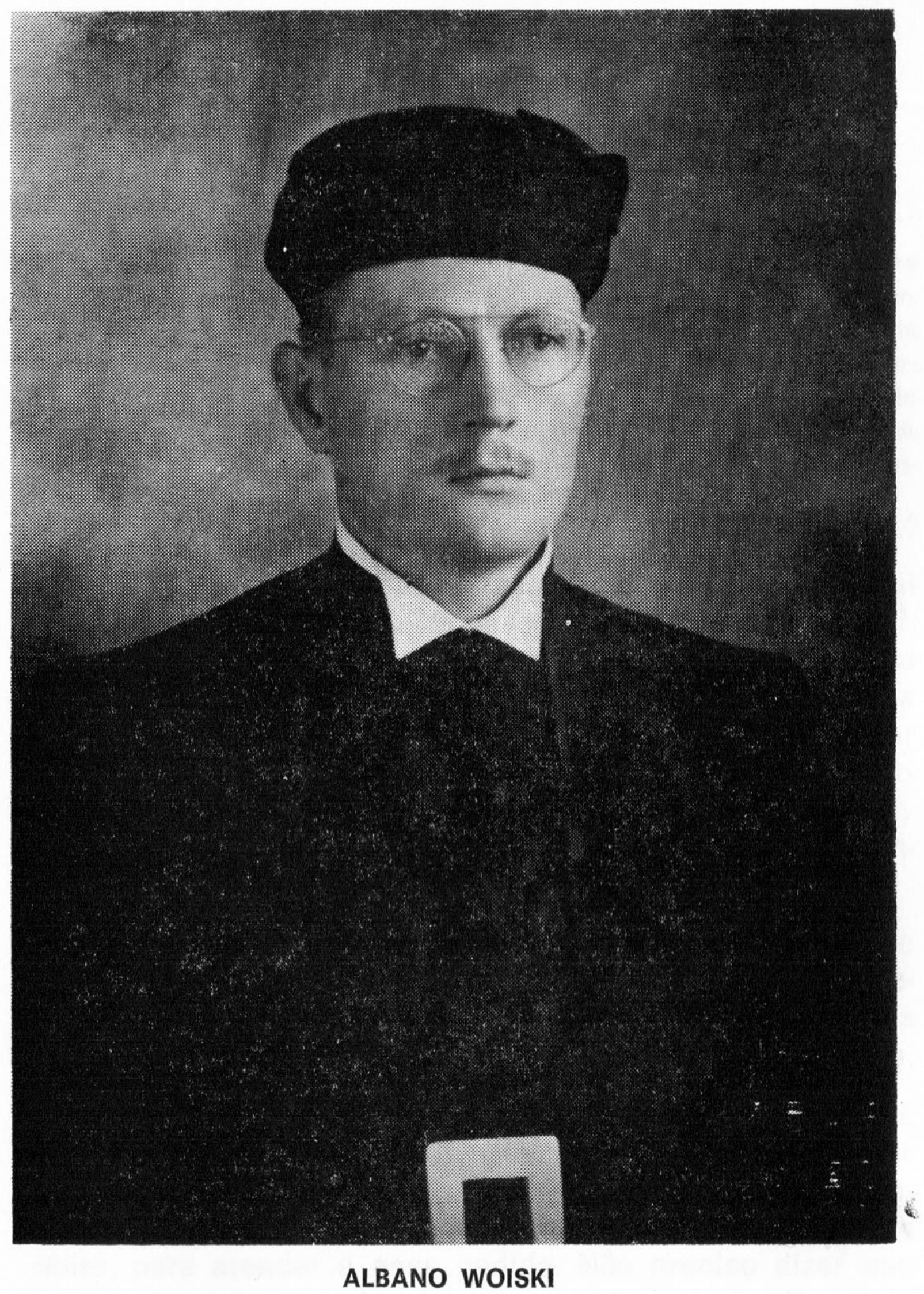

Educar, Curitiba, 7(1/2):107-122, jan./dez. 1988 


\section{ENTREVISTA COM O PROFESSOR ALBANO WOISKI}

Esta entrevista foi realizada pelos professores Niroá Rotta Ribeiro Glaser e Antônio Lineu Carneiro, com a presença da profa. Mary Terezinha Paz Brito. A parte técnica de gravação esteve a cargo de Waldomiro Vicente de Souza, do Centro de Recursos Audiovisuais do Setor de Educação. A transcrição foi de Afonso Gava, técnico em assuntos culturais, locado no mesmo setor da UFPR.

NIROÁ - Com grande satisfação nos encontramos aqui na sala 101 do Setor de Educação, reunidos com o prof. Albano Woiski, para uma conversa rememorativa e ao mesmo tempo comemorativa em torno dos cinqüenta anos do Curso de Pedagogia. Professor Woiski, poderá o senhor nos dizer quando e por que motivo resolveu seguir a carreira do magistério e optou pelo Curso de Pedagogia?... $\mathrm{O}$ que o levou, enfim, a pensar em Pedagogia como compromisso profissional?

WOISKI - Bem, na questão da escolha de trabalho, se quiserem, a vocação para alguma atividade útil à sociedade... isso é um problema muito difícil de dizer... Mas tudo me leva a crer que eu nasci para servir aos outros.

Em 1941 eu fui contratado pelo Colégio Novo Ateneu, a convite do prof. Elísio de Oliveira Viana, para lecionar um curso noturno de admissão. Pensei um pouco. Eu trabalhava no comércio e resolvi dedicar algumas horas, à noite, para atender a esse pedido. Não preciso dizer que isso fazia parte também do meu espírito cristão. Era mais 
ou menos como uma responsabilidade do cristão. E ressa condição eu fui até... eu já não lembro bem, mas fui continuando e passei a ser professor do ginásio e, dep̧ois, do científico... isto, agora recordo, até junho de 1951.

Bem, é interessante esta pergunta porque muita gente já me questionou: por quê, em vez de estudar Direito ou Medicina, você resolveu estudar Pedagogia?!

Novamente, é difícil responder. Mas a decisão foi instantânea. Em 1941, eu me inscrevi para o vestibular de Pedagogia. Passei. Naquele tempo o vestibular era escrito e oral; passei em primeiro lugar, mas isso não era grande vitória, porque havia as matérias de Português e História e eu lia muito... Eu freqüentava a Biblioteca Pública, aqui em Curitiba, quando era ainda na Rua São Francisco, se não me engano. Era uma biblioteca pequenininha... Também na Congregação Mariana dos Jovens da Catedral, de que eu fazia parte, havia uma biblioteca muito boa e eu, então, lia muito... principalmente essas aventuras de Emílio Salgari. É... enfim, eu lia muito e gostava mesmo de ler. E na minha casa, meu pai também tinha alguns livros, sobretudo relacionados com a nossa Curitiba que, naquele tempo, devia ter aí uns setenta mil habitantes. Já no Grupo Escolar, anexo à Escola Normal, havia uma biblioteca e eu me recordo que tínhamos horário de leitura e não podíamos levar os livros para casa; mas líamos com a tarefa de fazer um resumo da leitura. E lembro-me de que, em certa ocasião, eu tive de escrever um trabalho sobre Tiradentes - cada aluno fazia seu trabalho e o tinha que ler na sala de aula. A prof. ${ }^{a}$ Estella do Rego Barros, agora já falecida, elogiou muito meu trabalho, dizendo que parecia ter sido tirado de um livro... e, na realidade, foi na leitura de uma revista que era editada, se não me engano, pelo Clube Curitibano, que encontrei aquelas idéias sobre Tiradentes e... alcancei ganhar uma distinção pelo meu trabalho. Tudo isso contribuiu para me levar à Pedagogia. Eu não sabia direito o que era, 
mas na Congregação Mariana encontrava-me com o saudoso Dr. Rosário Farani Mansur Guérios, nos tornamos amigos e eu lhe perguntei o que era Pedagogia. E recordome muito bem de como ele disse: "A Pedagogia é a porta de entrada para os valores humanos". Essa compreensão parece ter-me levado a deixar de lado o Direito, a Medicina, a Engenharia, a Química e a Física... Parece-me que eu era humanista desde o grupo escolar... Quem sabe, não teria sido a prof. Estella do Rego Barros quem plantou em mim essa semente, pelo valor que ela dava à leitura e ao homem. Outros fatos, já nos tempos do grupo escolar, levaram-me a valorizar o homem.

O capitão Adir Guimarães foi o primeiro piloto que veio com um aeroplano (naquele tempo era de asas duplas ainda) do Rio de Janieiro a Curitiba, sozinho, numa viagem sem escala. $O$ fato é que o Grupo Escolar Anexo à Escola Normal foi todinho, de bonde, até o Portão que, naquele tempo, era simplesmente um campo; chamava-se Portão porque era mesmo o portão de Curitiba... Os trens entravam por ali e iam adiante, até Morretes, Antonina e Paranaguá. E o avião desceu. Havia uma multidão, mas nós, do Grupo Escolar, estávamos lá. E eu me recordo também de um dos discursos - não lembro mais de quem... de um político? - que enfocou o valor do homem, naquela festividade. Numa outra circunstância, todo o Grupo Escolar fez uma visita a uma fábrica de telhas, de tijolos... (não recordo, mas se não me engano, era Baggio) e a professora explicou o valor do homem, fazendo pratos, telhas, tijolos... Uma outra visita foi a uma fábrica de garrafas, não lembro mais o local, mas os comentários da professora também valorizaram o homem. Então, tudo isso deve ter sido uma semente que caiu na minha vida $e .$. eu resolvi tornar-me pedagogo. Naquele tempo, era uma espécie de diferença ser pedagogo - porque havia o professor que era médico, engenheiro, advogado, como os que davam aulas no Ginásio Paranaense, que eu também 
freqüentei. E havia as professoras normalistas. Então, pedagogo parecia uma diferença muito grande, que deveria ser conquistada em um curso superior...

A minha turma de Pedagogia não passava de nove pessoas e nós tínhamos aulas à tarde. Umas disciplinas... assim, não lembro, mas havia Complementos de Matemática - que nos levou a estudar novamente Matemática, para compreendermos os cálculos estatísticos. Começamos também a estudar Sociologia. Era uma palavra cheia... Nós the dávamos muito valor porque o professor era Bento Munhoz da Rocha Netto. Ele não era ainda político, era engenheiro da Caixa Econômica. Ele então me deu, junto com outros colegas, o valor da presença do professor dentro do horário das aulas. O prof. Bento saía da Caixa às 5 h00 da tarde e às 5 h50 estava na sala de aula para nos dar Sociologia. Esta disciplina humanizou-me de forma extraordinária, porque Bento Munhoz da Rocha Netto era humanista. Ele fazia parte do Círculo de Estudos Bandeirantes que, aqui em Curitiba, colocava o valor do homem como construtor da sociedade, diferentemente de outras teorias, que viam o homem como escravo da sociedade. Já naquele tempo falava-se muito em sociologia materialista, comunista, etc. O prof. Bento nos colocou dentro da sociologia cristã. Só havia um livro na linha dessa doutrina, o de Alceu Amoroso Lima - Tristão de Athaíde. Esse livro foi analisado de ponta a ponta, eu guardei os cadernos de anotação e posso dizer que o prof. Bento me deu o perfil do sociólogo.

O prof. Liguaru do Espírito Santo tinha duas disciplinas. Ele também era modelo de horário. Trabalhava no Banco de Londres, mas na hora certa estava lá ele com a Introdução à Filosofia e a Filosofia da Educação. Figura extraordinária de professor, chamava a cada um de nós também de professor... Lembro-me de quando, na apresentação de um trabalho, ele saiu do seu púlpito (que ainda existia nas salas de aula) e disse-me porque o meu 
nome principiava pela letra $A$ : - prof. Albano, assuma a mesa dos trabalhos! Eu fui o primeiro, era sobre a família, trabalho de Filosofia da Educação. Ele deixou-me comovido; eu era um simples aluno do $2 .^{\circ}$ ano de Pedagogia. Comecei a ler o que tinha escrito e ele, então, orientou-me: - Um momento, prof. Albano! um professor não deve ler, porque isso qualquer aluno sabe fazer. $O$ senhor só deve ter anotações e vai colocá-las na pedra segundo um esquema: 1 - Introdução. 2 - Desenvolvimento 3 - Conclusão. Foi a maior lição que recebi na minha vida.

Um outro professor, também de Pedagogia - năo por formação, mas pedagogo de alma -, Lauro Esmanhoto, nos dava duas disciplinas: uma era Educação Comparada e a outra... não posso lembrar. Como os demais professores, estava entre os primeiros a entrar e os últimos a sair, cumpridor do horário e tendo, como todos, alta consideração pelos alunos, como se fôssemos já seus colegas...

Então, esse Curso de Pedagogia que principiou em 1941, por força de lei terminou em 1945, porque só havia o bacharelado. Mas, justamente em fins de 45 ou início de 46, a lei permitiu que os bacharéis em Filosofia, Ciências e Letras da Universidade Federal do Paraná pudessem e devessem completar um Curso de Didática. Em 1946, portanto, freqüentamos o Curso de Didática. Éramos em nove alunos. O nosso professor era um advogado de renome, Hostílio de Souza Araújo. Como ele mesmo confessou, para que funcionasse a disciplina, ele teve que estudar um livro de Didática. E foi de uma eficiência extraordinária, de maneira que, em 1946, em dezembro, nove alunos, entre eles eu, terminamos o Curso de Pedagogia, que já existia desde 1938. Neste ano colou grau comigo, naquela mesma turma, mas em outra disciplina, o querido Irmão Albano, que era secretário eficientíssimo da Facul- 
dade de Filosofia, Ciências e Letras, que funcionava na Rua XV, no prédio dos Irmãos Maristas.

O tempo foi passando e, em 1948, o prof. Lauro Esmanhoto foi eleito vereador de Curitiba. Talvez por indicação dele, nesse mesmo ano, eu o substituí na disciplina de Educação Comparada. De modo que, como deve constar das Atas da Faculdade, naquela época, eu passei a professor assistente do prof. Lauro Esmanhoto. Aí começou minha escalada, difícil, na Universidade do Paraná, até o Doutorado em Didática Geral e Especial. Em 1951, por decreto do presidente Getúlio Vargas, passei, como publicado no Diário Oficial, a professor auxiliar de Didática Geral da Faculdade de Filosofia, Ciências Letras da Universidade Federal do Paraná. A Didática Especial ficou com outros professores Não mais existia o título de professor substituto, cargo que eu assumira por indicação do prof. Homero Batista de Barros, que me considerou substituto capaz na disciplina de Didática Geral quando o prof. Hostílio de Souza Araújo passou a professor do Curso de Direito da UFPR e não podia acumular cargos. E eu recordo do que me disse o prof. Hostílio: "- Melhor didata do que eu, somente o senhor!" Então, assumi a disciplina. Bem, acontecia que dentro de dois anos o professor auxiliar deveria fazer concurso ou tornar-se livre-docente em qualquer universidade mundial.

O prof. Homero Batista de Barros chamou-me an seu gabinete e disse: "- Aí está o regulamento. As purtas estão abertas para o senhor fazer a sua Docência-Livre, porque não temos possibilidade de mandá-lo para São Paulo!" (Onde, parece-me, já havia o Mestrado em Pedagogia, na USP). Passei, então, a consultar o prof. Liguaru Espírito Santo, em sua casa, na sua biblioteca. Com toda a gentileza, ele disse-me: "- Pode escolher o livro que o senhor quiser para fazer sua tese de docência e eu estarei a sua dispoisção para auxiliá-lo naquilo que me for possível e que seja da minha competência " Conversamos 
e discutimos e tal... e a idéia foi dele:" - Por que o senhor não coloca o cinema como auxiliar do professor na sala de aula?" Naquele tempo só existia o cinema educativo do prof. Roquete Pinto, no Rio de Janeiro. E aí me surgiu a idéia de fazer uma Cinematográfica Pedagógica. Trabalhei sozinho, porque o prof. Liguaru estava com muitas incumbências no Banco e na Universidade. Ele só me poderia atender à noite.

Mas em 1953, no dia 29 de março, defendi minha tese de docência. Creio que fui o primeiro professor de Pedagogia a defender tese, em nossa Universidade.

LINEU - A partir deste momento, seguindo a sua elaboração até agora, gostaríamos que o senhor nos colocasse, então, quais os fatos ou momentos que mais marcaram a sua convivência com os colegas nesta Instituição e, também, com o corpo docente!

WOISKI - Esta pergunta é bastante relevante para a minha vida porque em 1958, se não estou enganado, houve a inauguração do prédio da Faculdade de Filosofia, Ciências e Letras da Universidade Federal do Paraná. E a Pedagogia funcionava no mesmo prédio, de modo que havia uma vizinhança muito querida entre os professores de Pedagogia, de Filosofia, de Letras, de História, de Matemática e de Biologia (História Natural) - nós nos encontrávamos principalmente na biblioteca e, de modo especial, na cantina. E então intensificou-se a convivência com os colegas que se haviam formado em 1946, em outros cursos. Freqüentávamos a cantina em um clima de muita amizade, trocando idéias e promovendo festividades, bem como a defesa de direitos. Deste modo, numa certa ocasião, a profa. Cecília Westphalen teve a idéia maravilhosa da fundação de uma Associação dos Antigos Alunos da Faculdade de Filosofia, Ciências e Letras da Universidade do Paraná. 
Eu tive a honra de ser escolhido, numa das eleições, para presidir essa associação, que foi de grande valia para a defesa dos direitos dos licenciados no Paraná, pois ainda não existiam as atuais Universidades de Londrina, Ponta Grossa e Maringá. Nessa época, o Governo do Estado resolveu fazer um concurso chamado dos "Mil Dias". Isto significava que quem tivesse 1.000 dias de função pública no Brasil, no Paraná ou em Curitiba, em qualquer circunstância e sem precisar ser licenciado, poderia fazer concurso para o Colégio Estadual do Paraná. Isso, de certa forma, era um acinte aos licenciados que se tinham formado em Química, Física, Matemática, Geografia, História etc... enfim, que queriam ser professores, tinham esse direito, mas o seu título passava a valer menos que os 1.000 dias de qualquer funcionário público. Por esta ocasião, a Profa. Cecília Westphalen, eu e vários outros licenciados, já dentro da Associação dos Licenciados do Paraná, saímos em passeata, creio que pela primeira vez no Brasil... Atravessamos a Rua XV de Novembro e fomos à Secretaria de Educação para protestar. Quase nada conseguimos. Mas, depois de muita discussão pelo rádio (não havia ainda TV) e nas rodas da Rua XV - onde Cecília Westphalen e eu fomos vilipendiados, aparecendo enforcados em dois cartazes... creio que no café Belas Artes - contratamos, como Associação, um advogado para nos defender. E ganhamos a questão!

Este feito foi bastante expressivo na época, chamando a atenção dos poderes públicos para com os professores do Paraná. O prof. Robine, da primeira turma de licenciados da Universidade do Paraná e que era diretor do Colégio Estadual do Paraná, achou muito expressivo o resultado da nossa luta, entre outros que reconheceram já ter o licenciado, no Paraná, o seu lugar e a sua vez: lembro, inclusive, que um deputado paranaense... seu nome escapa-me agora, fez constar essa vitória nos Anais da Assembléia Legislativa do Estado - vitória alcançada pelo Dr. 
Laertes de Macedo Munhoz, como nosso advogado. Este fato repercutiu até em São Paulo, chamando a atenção para o problema dos liceniciados.

Bem, a minha carreira foi sendo conquistada mediante títulos que consistiam de provas e publicações. A primeira prova era para professor assistente, mas só poderia ser assistente quem fosse docente-livre. Tendo esta qualificação, submeti-me à prova para assistente. Eram mais valorizadas as publicações e recordo-me então, de que a revista Panorama estava iniciando sua caminhada, com Adolfo Soethe; conversando com ele, foi-me facultada uma página final para que eu fosse publicando algo sobre Educação e Pedagogia. Também o então arcebispo, D. Manoel da Silveira d'Elboux, pediu-me que fizesse, nessa página, a valorização do professor como construtor da sociedade, através da família; era uma campanha que ele estava fazendo. Todo mês saía um artigo de minha autoria e isto muito valeu para tornar-me professor assistente.

O próximo degrau era o de professor adjunto. Essa promoção era mais por títulos, especificamente o título de doutor. Recebi esse título por uma concessão do Governo da República, pela qual todos os docentes livres passaram a doutores. Vários colegas receberam comigo essa titulação, que era também condição para inscrição ao concurso de catedrático.

E aí então, em 1965, apresentei minha tese para a cátedra. Esta tese era sobre o Estudo Dirigido, fruto de um trabalho realizado no Colégio Estadual do Paraná, com os professores e até com antigos alunos meus na Universidade, que passaram a fazer parte do Ginásio Experimental, criado em 1950 pelo presidente Dutra. Mas não defendi minha tese por causa de um decreto presidencial que protelava todas as defesas de tese no Brasil inteiro para um tempo oportuno, porque estavam em curso modificações institucionais nas universidades públicas, que 
passaram a ser tituladas como federais. Pouco mais tarde, quem tivesse já apresentado sua tese para a Comissão de Concurso, também já estabelecida, veio a receber a qualificação de titular - não mais de catedrático; e assim é que, por uma circunstância alheia à minha vontade, tornei-me titular sem ter defendido o ponto de vista da minha tese sobre o tema tratado.

O interessante desta minha jornada, na UFPR, é que a Faculdade de Filosofia, Ciências e Letras desapareceu com a chegada do Institutos e das Faculdades Especiais. Foram criados os Institutos de Química, de Matemática, de Física etc. e a Faculdade de Educação. Isto em 1970. E aí minha vida cruzou com uma figura extraordinária - Dr. Brasil Pinheiro Machado. Magistrado e humanista também, assumiu a direção da Faculdade de Educação, pois, caso contrário, ela teria sido absorvida pela Faculdade de Filosofia, Ciências e Letras. A Faculdade de Educação, pela decisão do prof. Brasil, constituiu um fato inteiramente novo nesta instituição universitária; mas toIhido de continuá-la dirigindo, por impossibilidades particulares em sua carreira e por encargos com a própria família, o prof. Brasil indicou (e o pedido foi aceito) a profa. Zélia Milléo Pavão, que fora minha aluna de Didática, para que assumisse a direção. E daí em diante a Faculdade de Educação caminhou até se tornar um Setor dentro da própria Universidade.

Em 1971 se não estou enganado, o Departamento de Método e Técnicas da Educação nasceu, dentro do Setor de Educação. E nasceu pelas minhas mãos. Éramos simplesmente quatro professores: as prof. ${ }^{\alpha *}$ Eny Caldeira, Dinalva Frota Cordeiro Guimarães, Hercília de Morais Sarmento, minha ex-aluna... e eu. Num primeiro momento de expansão, por necessidade de atendimento aos alunos das Licenciaturas, agregaram-se a nós quatro: a prof. Maria das Dores Wouk, que deixou o Departamento de Letras, onde lecionava Francês; o prof. Werner Arthur Con- 
rado Barthelmess, que veio de Química; e sua esposa, a prof. Heloísa Barthelmess, do Departamento de Geografia; e o prof. Antônio Lipski, de Filosofia. Assim, as Didáticas Especiais começaram a funcionar a todo o vapor, para formar professores já dentro de uma linha de atuação: professores de Química, de Letras, de Geografia, Filosofia, etc. Tenho a dizer que o Setor de Educação, por parte da sua Direção e dos demais Departamentos, sempre deu muito apoio às atividades e trabalhos próprios do Departamento de Métodos e Técnicas da Educação, favorecendo o seu crescimento quantitativo e qualitativo.

Um fato bastante expressivo na vida do Departamento, no âmbito do meu envolvimento e contribuição, foi um convênio estabelecido com a Secretaria da Educação em vista dos estágios obrigatórios para os licenciandos, em suas diferentes atividades; assim é que alunosmestres de Matemática, de Química, de Física, etc. tiveram um laboratório de Prática de Ensino no Colégic Estadual do Paraná. Era um laboratório de trabalho e de pesquisa no ensino, servindo às Classes Integrais do Colégio Estadual do Paraná - classes essas que eu tive também a ocasião de fundar, por uma liberalidade do então diretor, prof. Ulisses de Mello e Silva.

Bem, nesta altura, gostaria de referir-me a outro momento importante na minha carreira de professor universitário: o Curso de Mestrado do Setor de Educação da UFPR. Convidaram-me os prof." Lauro Esmanhoto e Olga Mattar e, então, começamos a procurar quem poderia, segundo as condições exigidas, fazer parte do corpo docente em nível de pós-graduação. Foi um trabalho difícil porque só poderiam ser indicados docentes-livres e doutores. Mas conseguimos... E eu resolvi lecionar uma disciplina que não existia no Brasil: Didática Experiencial. Para mim foi uma experiência extraordinária, porque eu estava colocando em linha de ação uma proposta muito difícil - as idéias de Carl Rogers. Tudo me leva a crer 
que foi a primeira vez, no Brasil, que alguém aplicou as propostas de Rogers numa prática educacional e num curso de pós-graduação.

NIROÁ - Prof. Woiski: especificamente com respeito ao Curso de Pedagogia da Universidade Federal do Paraná, que balanço o senhor faria desses cinqüenta anos de história?

WOISKI - O Curso de Pedagogia... ele começou engatinhando, balbuciando, porque o pedagogo só poderia lecionar Filosofia e Matemática. Eram os seus direitos, após a formatura. E aí está uma das razões pelas quais me tornei professor de Filosofia no antigo Ginásio Paranaense, em 1948, dois anos após minha colação de grau. Eu trabaIhava no Colégio Novo Ateneu e o prof. Felício Raitani Neto me convidou para ser professor de Filosofia à noite, atendendo a uma turma; lembro que era a época dos blecautes, após a Segunda Guerra Mundial. Eu aceitei e tornei-me professor de Filosofia por concurso em 1951, na administração do governador Bento Munhoz da Rocha Netto, que tinha sido meu professor.

Com o correr do tempo, a lei foi modificada e o Curso de Pedagogia passou a ser a sementeira para a Orientação Educacional e, assim, o pedagogo mereceu outras possibilidades de trabalho, de ocupação profissional. Com o surgimento do orientador educacional, os pedagogos começaram a atuar também nos cursos de formação dessa habilitação, em cursos superiores. No meu caso pessoal me tornei orientador educacional pela circunstância de ter fundado o Curso de Orientação Educacional na Universidade Católica do Paraná. Muitas outras possibilidades se abriram aos pedagogos nesses cinqüenta anos, desde 1938, de modo que passaram a ter novas áreas de atuação especializada, inclusive por meio de cursos em nível de pós-graduação. 
Bem, o Curso de Pedagogia, como eu o fiz e no qual atuei - na Universidade Católica do Paraná e aqui na Federal - em realidade, desapareceu... Ficou simplesmente o espírito pedagógico diluído, mas fermentando em várias disciplinas de natureza pedagógica e até mesmo em Departamentos da Universidade. Assim, como curso específico, é claro, ele ainda funciona e tem o seu grande valor mas a palavra pedagogo foi substituída por educador e, evidentemente, continua a produzir os seus efeitos.

No dia em que alguém desejar estabelecer um balanço dos cinqüenta anos da Pedagogia Paranaense, creio que não poderá esquecer que os pedagogos atuantes no Paraná e até mesmo fora do nosso Estado, foram em grande parte fruto da semente plantada no Curso de Pedagogia da antiga Faculdade de Filosofia, Ciências e Letras da untão Universidade do Paraná.

Assim é que os Cursos de Pedagogia surgidos nas cidades de Ponta Grossa, Londrina, Maringá, União da Vitória e Palmas, começaram a funcionar graças à presença e atuação eficiente de antigos alunos do Curso de Pedagogia da Universidade do Paraná.

Ademais, é preciso refletir que o Curso de Pós-Graduação em Educação da nossa Universidade também resultou do esforço e dedicação de educadores oriundos ou ligados ao Curso de Pedagogia, na sua fase inicial. E não posso olvidar que, inclusive, o Curso de Pós-Graduação em Direito da UFPR somente pôde ser instalado com a minha cooperação e titulação.

E de se lembrar ainda que inúmeros diretores de escolas de magistério, de ginásios e colégios municipais e estaduais ostentaram, e fazem-no até agora com honra, o diploma de pedagogos, conquistado no Curso de Pedagogia da Universidade do Paraná - ontem - e da Universidade Federal do Paraná — hoje. 
LINEU - Professor, finalmente, qual seria a sua mensagem, hoje, que o senhor nos poderia deixar?

WOISKI - A única mensagem que um velho professor poderia deixar é a seguinte, que eu aprendi do prof. Liguaru Espírito Santo, quando era seu aluno e que ele citava como sendo do grande pedagogo De Hovre: "A alma da Educação é a educação da alma". Se a Educação perder este sabor de valor humano, restará puramente a instrução. E instruir nada mais é que amontoar. O importante, para as crianças, é saber que existem valores humanos impostergáveis. Caso contrário, ficaremos somente com as individualidades que acabam formando massa. $\mathrm{E}$ a massa é amorfa, não tem direção própria. Ela vai para onde $a$ empurram. Educar, de uma certa maneira, é desenvolver valores, que demandam decisões de escolha, porque a expressão maior do ser humano traduzindo sua natureza diferenciada qualitativamente daquela dos animais, está em saber escolher com responsabilidade. Sem isso, o mundo caminha para a desordem e desumanização. A mensagem, portanto, é: humanizar! E no mais pleno sentido.

NIROÁ - Professor Woiski, nós queremos muito the agradecer a atenção e o tempo que o senhor dispensou a esta nossa entrevista e dizer que foi uma grande valia a gente poder contar mais uma vez com sua cooperação... Muito obrigado! em nome das comissões executiva e editorial da revista Educar. 